\title{
Multivesicular Release at Schaffer Collateral-CA1 Hippocampal Synapses
}

\author{
Jason M. Christie and Craig E. Jahr \\ Vollum Institute, Oregon Health and Science University, Portland, Oregon 97239
}

Whether an individual synapse releases single or multiple vesicles of transmitter per action potential is contentious and probably depends on the type of synapse. One possibility is that multivesicular release (MVR) is determined by the instantaneous release probability $\left(P_{\mathrm{r}}\right)$ and therefore can be controlled by activity-dependent changes in $P_{\mathrm{r}}$. We investigated transmitter release across a range of $P_{\mathrm{r}}$ at synapses between Schaffer collaterals (SCs) and CA1 pyramidal cells in acute hippocampal slices using patch-clamp recordings. The size of the synaptic glutamate transient was estimated by the degree of inhibition of AMPA receptor EPSCs with the rapidly equilibrating antagonist $\gamma$-D-glutamylglycine. The glutamate transient sensed by AMPA receptors depended on $P_{\mathrm{r}}$ but not spillover, indicating that multiple vesicles are essentially simultaneously released from the same presynaptic active zone. Consistent with an enhanced glutamate transient, increasing $P_{\mathrm{r}}$ prolonged NMDA receptor EPSCs when glutamate transporters were inhibited. We suggest that MVR occurs at SC-CA1 synapses when $P_{\mathrm{r}}$ is elevated by facilitation and that MVR may be a phenomenon common to many synapses throughout the CNS.

Key words: AMPA receptor; glutamate spillover; EPSC; NMDA receptor; synaptic vesicle release; glutamate transporters

\section{Introduction}

The simultaneous release of more than one vesicle from an individual presynaptic active zone can affect the strength and reliability of synaptic transmission (Wadiche and Jahr, 2001; Foster et al., 2002; Oertner et al., 2002). At many central synapses, however, release caused by a single presynaptic action potential is limited to one vesicle [univesicular release (UVR)] (Gulyás et al., 1993; Lawrence et al., 2003; Silver et al., 2003; Murphy et al., 2004; Biró et al., 2005; Sargent et al., 2005). Thus far, unifying or predictive characteristics of these synapses have not emerged. Although the likelihood of multivesicular release (MVR) at particular synapses has been tied to release probability $\left(P_{\mathrm{r}}\right)$ (Foster et al., 2002; Oertner et al., 2002; Wadiche and Jahr, 2001), the ability of a synapse to release multiple vesicles does not seem to correlate with basal $P_{\mathrm{r}}$. For example, MVR is the norm at the high $P_{\mathrm{r}}$ climbing fiber-Purkinje cell synapse (Wadiche and Jahr, 2001; Foster et al., 2002) but not at the high $P_{\mathrm{r}}$ olfactory nerve-periglomerular cell synapse (Murphy et al., 2004). Whether MVR can occur at Schaffer collateral (SC)-CA1 synapses, at which $P_{\mathrm{r}}$ ranges widely, is controversial (Stevens and Wang, 1995; Hjelmstad et al., 1997; Hanse and Gustafsson, 2001; Oertner et al., 2002).

Morphological examinations of SC-CA1 synapses indicate that multiple vesicles are docked at presynaptic active zones and each docked vesicle is a potential site of release (Schikorski and Stevens, 1997, 2001). If each docked vesicle can fuse indepen-

Received 0ct. 10, 2005; revised Nov. 7, 2005; accepted Nov. 8, 2005.

This work was supported by National Institute of Health Grants MH074989 (C.E.J.) and NS07381 (J.M.C.). We thank the members of the Jahr laboratory, including John Harrison, Melissa Herman, Ko Matsui, Richard Piet, and Jacques Wadiche, for suggestions and insightful discussions.

Correspondence should be addressed to Jason M. Christie, Vollum Institute, Oregon Health and Science University, 3181 SW Sam Jackson Park Road, Portland, OR 97239. E-mail: christij@ohsu.edu.

D01:10.1523/JNEUROSCI.4307-05.2006

Copyright $\odot 2006$ Society for Neuroscience $\quad$ 0270-6474/06/260210-07\$15.00/0 dently in a probabilistic manner, then the simultaneous release of more than one vesicle (MVR) could occur, the frequency of which would depend on $P_{\mathrm{r}}$. Consistent with the probabilistic fusion of multiple independent vesicles from the same site, Oertner et al. (2002) found that the potency of NMDA receptormediated responses at individual pyramidal cell spines increased with $P_{\mathrm{r}}$. However, minimal stimulation studies have reported that release at this synapse is restricted to UVR (Stevens and Wang, 1995; Hjelmstad et al., 1997; Hanse and Gustafsson, 2001). An increase in response potency could alternatively be attributed to glutamate spillover from neighboring synapses (Barbour and Haüser, 1997; Rusakov and Kullmann, 1998; Arnth-Jensen et al., 2002) or fusion pore regulation (Choi et al., 2000; Renger et al., 2001).

In this report, we investigate transmission at SC-CA1 synapses using a rapidly equilibrating competitive antagonist (Clements et al., 1992; Tong and Jahr, 1994; Wadiche and Jahr, 2001). We find that the concentration of glutamate in the synaptic cleft depends on $P_{\mathrm{r}}$. Glutamate spillover does not contribute to the peak EPSC amplitude, nor is there evidence for fusion pore regulation. These results indicate that MVR can be prominent at this synapse and suggest that MVR is a mechanism that can alter synaptic strength at many synapses in the CNS.

\section{Materials and Methods}

Slice preparation. Acute hippocampal brain slices were prepared from Sprague Dawley rats [postnatal day 14 (P14) to P21] in accordance with Oregon Health and Science University Institutional Animal Care and Use Committee protocols. After anesthesia, rats were decapitated and the hippocampi were removed. Transverse slices $(250-400 \mu \mathrm{m})$ were cut on a vibroslicer (Leica, Nussloch, Germany) in ice-cold solution containing the following (in mM): $127 \mathrm{NaCl}, 2.5 \mathrm{KCl}, 1.25 \mathrm{NaH}_{2} \mathrm{PO}_{4}, 1.5 \mathrm{CaCl}_{2}, 1.5$ $\mathrm{MgCl}_{2}, 25 \mathrm{NaHCO}_{3}$, and $25 \mathrm{D}$-glucose (saturated with $95 \% \mathrm{O}_{2}-5 \% \mathrm{CO}_{2}$ ). Slices were transferred to a warmed bath $\left(35^{\circ} \mathrm{C}\right)$ of the same solution for $30 \mathrm{~min}$ and then incubated at room temperature. 
Experimental procedures. Whole-cell recordings from CA1 pyramidal cells were obtained under visual control using differential interference contrast optics (Zeiss, Thornwood, NY) in the above solution $\left(32-35^{\circ} \mathrm{C}\right)$ with picrotoxin $(100 \mu \mathrm{m})$ to block $\mathrm{GABA}_{\mathrm{A}}$ receptors. In addition, 3-(( $R)$-2-carboxypiperazin)-propyl-1-phosphonic acid ( $R$-CPP) $(5 \mu \mathrm{M})$ and $(5 S, 10 R)-(+)-5$-methyl-10,11-dihydro-5H-dibenzo[a,d]cyclohepten-5,10-imine maleate (MK801) $(10 \mu \mathrm{M})$ were added to isolate AMPA EPSCs. Tetrodotoxin $(1 \mu \mathrm{M})$ was applied at the end of each experiment to allow the stimulus artifact to be subtracted from the synaptic response. When recording NMDA EPSCs, 2,3-dioxo-6-nitro-1,2,3,4tetrahydrobenzo[f] quinoxaline-7-sulfonamide (NBQX) $(20 \mu \mathrm{M})$ and Dserine $(10 \mu \mathrm{M})$ were instead added to the perfusate. Cells were held at -70 or $+40 \mathrm{mV}$ for AMPA or NMDA receptor-mediated responses, respectively. Patch pipettes (2.5-5 M $\Omega$ ) contained a solution of the following (in mM): $130 \mathrm{Cs}^{+}$methanesulfonate, $4 \mathrm{NaCl}, 10 \mathrm{Cs}$-BAPTA, 4 $\mathrm{Mg}_{2}$ ATP, 0.4 $\mathrm{Na}_{2} \mathrm{GTP}$, and 10 HEPES, pH 7.3.

Synaptic transporter currents were recorded from astrocytes located in stratum radiatum in area CAl as described previously (Bergles and Jahr, 1997). Currents were evoked in a bath solution containing the following (in $\mu \mathrm{M}$ ): 100 picrotoxin, $5 \mathrm{R}$-CPP, $10 \mathrm{MK} 801$, and $20 \mathrm{NBQX}$. External $\mathrm{Ca}^{+2}$ and $\mathrm{Mg}^{+2}$ were adjusted to 2.5 and $0.5 \mathrm{~mm}$, respectively, to enhance the amplitude of the response by increasing $P_{\mathrm{r}}$. The holding potential was set at the resting potential (approximately $-90 \mathrm{mV}$ ). Afferent stimulation elicited transients consisting of both fast and slow components. The fast transporter-mediated current was isolated from the slow potassium-mediated conductance (Bergles and Jahr, 1997) with a DLthreo- $\beta$-benzyloxyaspartic acid (TBOA) $(100 \mu \mathrm{M})$ subtraction protocol. $\mathrm{K}^{+}$methanesulfonate replaced $\mathrm{Cs}^{+}$in the internal solution.

Electrophysiological recordings were made with Molecular Devices (Union City, CA) amplifiers. The analog signals were filtered at $2 \mathrm{kHz}$ and digitized at $10 \mathrm{kHz}$. Data were collected using custom software (J. S. Diamond, National Institute of Neurological Disorders and Stroke, Bethesda, MD) written in IgorPro (WaveMetrics, Lake Oswego, OR). Series resistance was compensated $\sim 80 \%$ for pyramidal cells but not for astrocytes. Schaffer collateral/commissural fibers were stimulated with a glass electrode placed in stratum radiatum $\sim 30-100 \mu \mathrm{m}$ from the cell body. Brief electrical pulses $(10-100 \mu \mathrm{s} ; 10-80 \mathrm{~V})$ delivered at $0.2 \mathrm{~Hz}$ evoked transmitter release. The border between area CA1 and CA3 was cut to reduce epileptiform activity in area CA1.

Data analysis and statistics. Cells were rejected from analysis because of poor stability [the paired-pulse ratio (PPR) recorded in wash diverged $\geq 10 \%$ from control] or poor voltage clamp (the PPR in NBQX diverged $\geq 10 \%$ from wash). Summary data are presented in several figures as normalized PPR. For these data, statistical tests compared results grouped as follows: the PPR recorded in $\gamma$-D-glutamylglycine ( $\gamma$-DGG) was compared with the average PPR of control and wash, the PPR in wash was compared with control, and the PPR recorded in NBQX was compared with the PPR in wash. Throughout this study, experiments were often repeated in the presence of the broad-spectrum metabotropic glutamate receptor (mGluR) antagonist LY341495 [(2S)-2-amino-2[(1S,2S)-2-carboxycycloprop-1-yl]-3-(xanth-9-yl) propanoic acid] (see Figs. 2, 3, 5). Results obtained in mGluR block did not differ from results obtained in the absence of the antagonist (see Fig. 2); therefore, the data were combined.

Statistical analysis was performed using Excel (Microsoft, Seattle, WA) and InStat (GraphPad Software, San Diego, CA). ANOVA and $t$ tests were used as appropriate. Reported values are presented as mean \pm SEM. Significance was considered as $p \leq 0.05$. In the figures, asterisks indicate statistical significance. Throughout this report, we have used $P_{\mathrm{r}}$ to qualitatively describe the overall amount of release without implying any specific mechanism.

\section{Results}

The synaptic concentration of glutamate varies with release probability

Neurotransmission between SC-CA1 synapses was studied using whole-cell recordings from rat hippocampal slices. Paired stimulation (40 ms interval) of afferent fibers evoked facilitating
$\mathrm{A} 1$
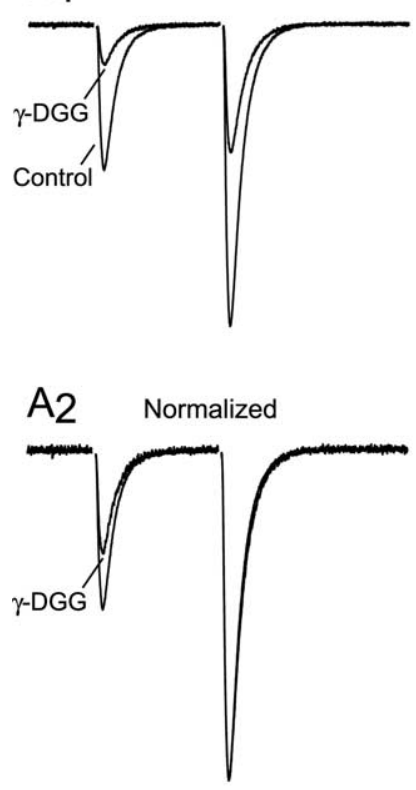

C

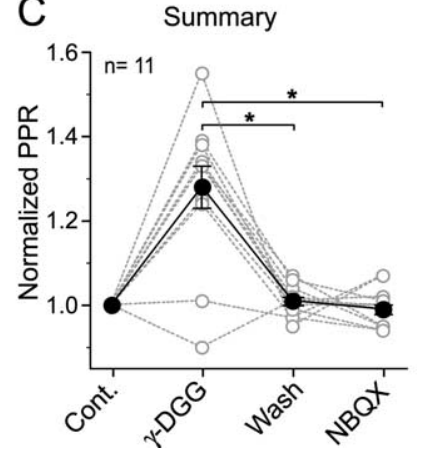

B1
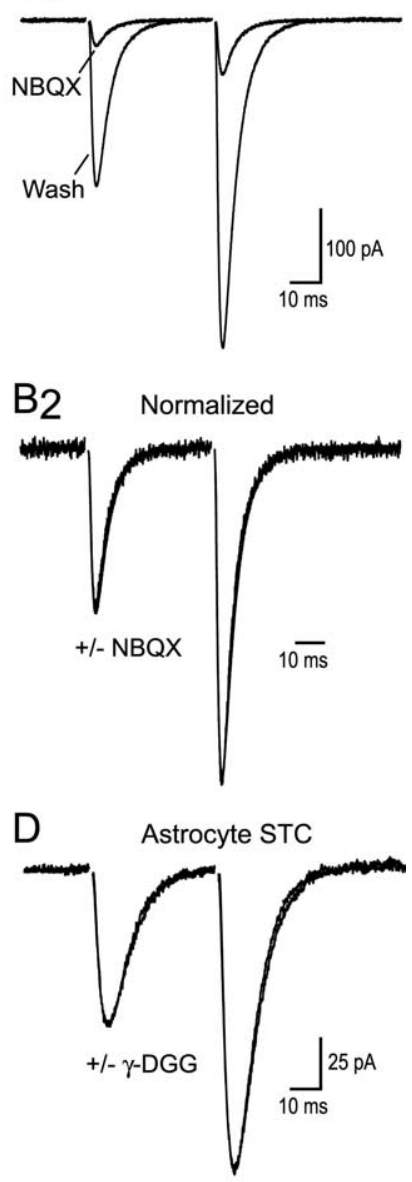

Figure 1. Paired-pulse EPSCs are differentially blocked by $\gamma$-DGG. $\boldsymbol{A}_{\boldsymbol{1}}$, AMPA receptormediated EPSCs evoked by paired stimuli $(40 \mathrm{~ms})$ in control and in $\gamma$-DGG $(2 \mathrm{~mm})$ are superimposed. $\boldsymbol{A}_{2}$, Traces from $\boldsymbol{A}_{\boldsymbol{1}}$ are normalized to the peak of the second EPSC. $\boldsymbol{B}_{\boldsymbol{1}}$, Paired EPSCs after $\gamma$-DGG washout and in NBQX (400 nM). $\boldsymbol{B}_{2}$, Traces from $\boldsymbol{B}_{\boldsymbol{1}}$, normalized to the peak of the second EPSC. C, Summary data show that PPR increases in the presence of $\gamma$-DGG. White circles represent the normalized PPR (see Materials and Methods) of individual experiments, and black circles are the mean values. Error bars indicate \pm SEM. $D$, STCs from area CA1 astrocytes are unaffected by $\gamma$-DGG (2 mM). All traces are the average of multiple responses.

AMPA receptor EPSCs in pyramidal cells (Fig. $\left.1 A_{1}\right)\left(\right.$ EPSC $_{1}$, $\left.-129.2 \mathrm{pA} ; \mathrm{EPSC}_{2},-251.3 \mathrm{pA} ; n=30\right)$. Such paired-pulse facilitation (PPF) reflects a short-term increase in $P_{\mathrm{r}}$ of presynaptic sites (Zucker and Regehr, 2002), and therefore PPF provides a rapid and reliable in-cell comparison of different $P_{\mathrm{r}}$ conditions.

To test whether an increase in cleft glutamate concentration accompanies a change in $P_{\mathrm{r}}$, as predicted by the MVR hypothesis, we measured the inhibition of paired synaptic currents produced by the low-affinity antagonist $\gamma$-DGG. The rapid equilibration kinetics of $\gamma$-DGG with AMPA receptors (Watkins et al., 1990; Liu et al., 1999; Wadiche and Jahr, 2001) results in competition for receptor binding even during the brief lifetime of glutamate in the cleft after exocytosis. Thus, AMPA receptor-mediated responses arising from a lower concentration of glutamate would be more effectively blocked by $\gamma$-DGG than responses arising from a higher glutamate concentration. $\gamma$-DGG ( $2 \mathrm{~mm}$ ) inhibited EPSC $_{1}$ by $68.5 \pm 3.0 \%$, whereas EPSC $_{2}$ was blocked by only $59.2 \pm 3.6 \%(n=11 ; p<0.01)$. Correspondingly, the PPR $\left(\mathrm{EPSC}_{2} / \mathrm{EPSC}_{1}\right)$ increased from $2.09 \pm 0.06$ to $2.68 \pm 0.15(n=$ 
$11 ; p<0.01)$ (Fig. $\left.1 A_{1}, A_{2}, C\right)$. To assess whether voltage-clamp error contributes to the differential block of $\gamma$-DGG, cells were challenged with a low concentration of the high-affinity antagonist NBQX (400 nM) after $\gamma$-DGG washout. Because of the slow dissociation rate of NBQX from AMPA receptors, glutamate does not compete with NBQX for receptor binding during its brief time in the synaptic cleft. Therefore, NBQX block is independent of the glutamate concentration. NBQX inhibited paired EPSCs to the same extent $\left(66.7 \pm 3.9\right.$ and $66.2 \pm 3.9 \%$, EPSC $_{1}$ and EPSC $_{2}$, respectively; $n=11$ ) and did not alter the PPR $(2.12 \pm 0.07$ and $2.16 \pm 0.07$, wash and NBQX, respectively) (Fig. $\left.1 B_{1}, B_{2}, C\right)$. These results suggest that the concentration of cleft glutamate increases during the second stimulation.

Manipulations that alter paired-pulse facilitation or depression often have a presynaptic locus. To confirm the postsynaptic specificity of $\gamma$-DGG, we measured synaptically activated glutamate transporter currents (STCs) in area CA1 astrocytes (Bergles and Jahr, 1997). STC recordings provide a sensitive measure of presynaptic release independent of postsynaptic receptor activity. $\gamma$-DGG $(2 \mathrm{~mm})$ did not alter the amplitude of either the first or second STC of a paired stimulation (100.9 \pm 0.8 and $99.6 \pm 0.7 \%$ of control, $\mathrm{EPSC}_{1}$ and $\mathrm{EPSC}_{2}$, respectively; $n=4$ ) (Fig. $1 D$.) This result indicates that the differential block of AMPA EPSCs by $\gamma$-DGG arises from a postsynaptic action.

\section{The contribution of spillover to the concentration of cleft glutamate}

Elevated concentrations of cleft glutamate evoked during PPF could arise from the simultaneous release of multiple vesicles from a single release site (MVR) (Tong and Jahr, 1994; Wadiche and Jahr, 2001; Oertner et al., 2002). Alternatively, accumulation of glutamate released from neighboring sites (spillover and pooling) could be responsible (Barbour and Haüser, 1997; Rusakov and Kullmann, 1998; Arnth-Jensen et al., 2002). If the second interpretation is true, then manipulations that specifically enhance spillover would decrease the $\gamma$-DGG inhibition of EPSCs.

Glutamate transporters located on astrocytes and neurons (Lehre and Danbolt, 1998; Ventura and Harris, 1999; Diamond, 2001) tightly regulate extrasynaptic transmitter diffusion and therefore spillover-mediated activation of adjacent synapses (Asztely et al., 1997; Bergles and Jahr, 1998; Diamond, 2001). As shown in Figure $2 A$, a subsaturating concentration of the competitive transporter antagonist TBOA $(10 \mu \mathrm{M})$ decreased the amplitude and prolonged the decay of astrocyte STCs (Fig. 2D). TBOA $(10 \mu \mathrm{M})$ also increased the amplitude and decay time constant of NMDA receptor EPSCs (Fig. $2 B, D$ ). These results are consistent with a temporal and spatial enhancement of the glutamate transient caused by diminished glutamate uptake. In contrast to NMDA responses, TBOA $(10 \mu \mathrm{M})$ did not affect the amplitude or the decay time course of the AMPA receptor-mediated EPSC (Fig. 2C,D) as seen previously with other transporter blockers (Hestrin et al., 1990; Sarantis et al., 1993). The preferen- tial prolongation of NMDA EPSCs by transport blockers may reflect their higher binding affinity for glutamate (Patneau and Mayer, 1990) and their slower desensitization rate than that of AMPA receptors. Glutamate spillover and pooling can lead to presynaptic mGluR activation (Scanziani et al., 1997) and therefore changes in $P_{\mathrm{r}}$. However, we did not observe a change in the PPR of either the AMPA EPSC $(97.9 \pm 1.1 \%$ of control; $n=7)$ or the diminished STC (97.7 $\pm 1.6 \%$ of control; $n=5)$, suggesting that $P_{\mathrm{r}}$ was not altered by TBOA. Despite this observation, we repeated the above experiments in the presence of the broadspectrum mGluR antagonist LY341495 $(50 \mu \mathrm{M})$. Similar results were obtained (Fig. 2 D), suggesting that mGluRs were minimally active in our conditions. These results indicate that incomplete inhibition of uptake enhances glutamate spillover without a change in presynaptic activity.

We next determined whether the $\gamma$-DGG sensitivity of AMPA EPSCs was diminished when glutamate spillover was enhanced. In the presence of TBOA $(10 \mu \mathrm{M}), \gamma$-DGG $(2 \mathrm{mM})$ altered the PPR to a similar extent as in the absence of TBOA $(2.12 \pm 0.08$ and $2.75 \pm 0.15$, control and $\gamma$-DGG, respectively; in TBOA, $2.17 \pm$ 0.07 and $2.84 \pm 0.1$, control and $\gamma$-DGG; respectively; $n=7$ ) (Fig. $3 A_{1}, A_{2}, B_{1}, B_{2}, C$ ). Consistent with this observation, $\gamma$-DGG inhibition of EPSC $_{1}$ and EPSC $_{2}$ was unaltered by TBOA (Fig. $3 D$ ). The most parsimonious explanation of this observation is that, even in conditions of slowed glutamate clearance, spillover does not enhance the glutamate transient responsible for the peak amplitude of the EPSC.

It is possible that the variations in cleft glutamate concentration arise from incomplete or a slowing of release through a nonexpanding fusion pore of exocytotic vesicles (Choi et al., 2000; Renger et al., 2001). In this interpretation, during low $P_{\mathrm{r}}$, partially fusing vesicles slowly expel their contents, eliciting a prolonged, 

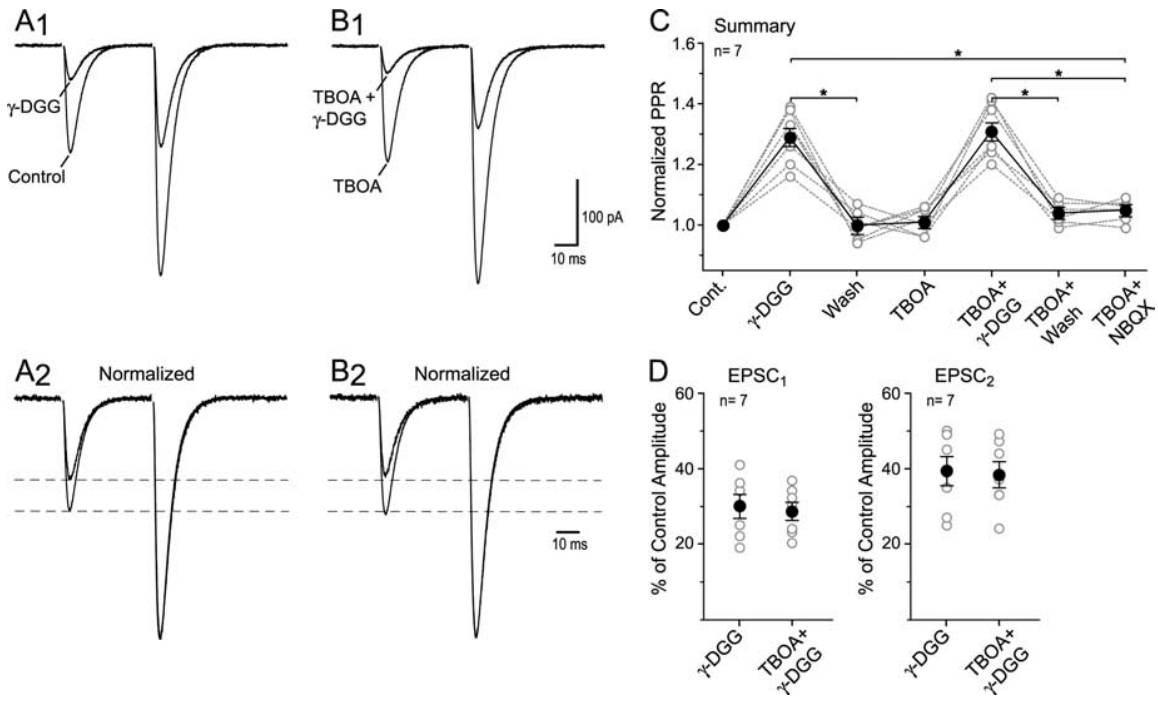

Figure 3. $\quad \gamma$-DGG inhibition is unaffected by glutamate uptake antagonism. $A_{1}$, AMPA receptor-mediated EPSCs in control and in $\gamma$-DGG $(2 \mathrm{mM}) . A_{2}$, Responses are normalized to the peak of EPSC ${ }_{2}$. $\boldsymbol{B}_{1}$, EPSCs in TBOA $(10 \mu \mathrm{M})$ and in TBOA plus $\gamma$-DGG $(2 \mathrm{mM})$. $B_{2}$, Normalized EPSCs show the differential block by $\gamma$-DGG. For comparison, dashed lines indicate the normalized peaks of EPSC in control and $\gamma$-DGG. C, Summary data show that the $\gamma$-DGG-dependent increase in the PPR was unaltered by uptake block. $\boldsymbol{D}$,

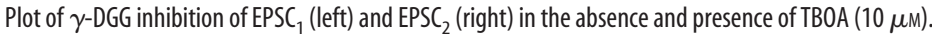
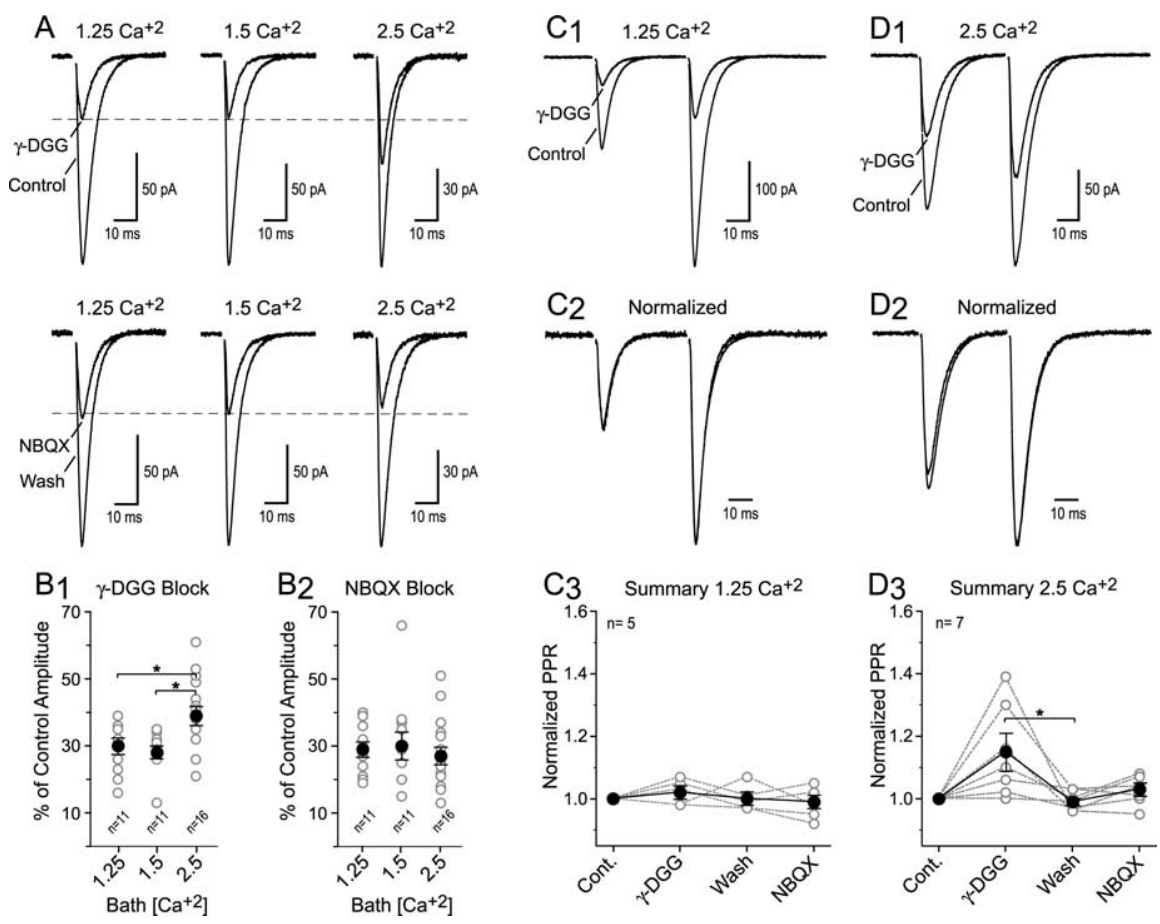

Figure 4. $\quad \gamma$-DGG inhibition depends on release probability. A, AMPA receptor-mediated EPSCs evoked in three $\mathrm{Ca}^{+2}{ }_{\mathrm{e}}$ conditions from three different cells. Responses from the same cell show inhibition by $\gamma$-DGG $(2 \mathrm{~mm})$ or NBQX ( $400 \mathrm{~nm})$ on the top and bottom, respectively. For comparison, dashed lines indicate the amplitude of the inhibited EPSC in $1.5 \mathrm{~mm} \mathrm{Ca}^{+2}{ }_{\mathrm{e}} \cdot \boldsymbol{B}_{1}$, Summary data show that $\gamma$-DGG inhibition was dependent on the $\mathrm{Ca}^{+2}{ }_{\mathrm{e}} \cdot \boldsymbol{B}_{2}$, NBQX inhibited EPSCs to the same extent. $\boldsymbol{C}_{1}$, AMPA receptor-mediated EPSC s evoked in $1.25 \mathrm{~mm} \mathrm{Ca}^{+2}$ in control and in $\gamma$-DGG $(2 \mathrm{mM}) . \boldsymbol{C}_{2}$, Traces from $\boldsymbol{C}_{1}$ normalized to the peak of the second EPSC. $\boldsymbol{C}_{3}$, Summary plot shows that the PPR was unaltered by $\gamma$-DGG. $\boldsymbol{D}_{1}$, EPSCs evoked in $2.5 \mathrm{~mm} \mathrm{Ca}{ }^{+2}$ in control and in $\gamma$-DGG $(2 \mathrm{~mm}) . \boldsymbol{D}_{2}$, Traces from $\boldsymbol{D}_{1}$ normalized to the peak of the second EPSC. $D_{3}$, Summary plot shows that $\gamma$-DGG, but not NBQX (400 nM), increased PPR.

low concentration transient of synaptic glutamate. When $P_{\mathrm{r}}$ is elevated, fusion proceeds rapidly and fills the cleft with a high concentration of glutamate. Therefore, the rise and decay of the EPSC should be faster at high $P_{\mathrm{r}}$ (Choi et al., 2000). We did not observe a kinetic change in the EPSC when $P_{\mathrm{r}}$ was altered with $\mathrm{PPF}\left(\mathrm{EPSC}_{1}, 0.86 \pm 0.06\right.$ and $4.50 \pm 0.12 \mathrm{~ms} ; \mathrm{EPSC}_{2}, 0.84 \pm 0.05$ and $4.47 \pm 0.12 \mathrm{~ms}, 20-80 \%$ rise and decay time constant, respectively; $n=22$ ) or external calcium $(0.91 \pm 0.09$ and $4.31 \pm$ $0.18 \mathrm{~ms} ; 0.82 \pm 0.06$ and $4.47 \pm 0.17 \mathrm{~ms}$, $20-80 \%$ rise and decay time constant for $\mathrm{EPSC}_{2}$ in 1.25 and $2.5 \mathrm{~mm}$ external calcium, respectively; $n=11$ and 16). Therefore, an increase in receptor activation with elevated $P_{\mathrm{r}}$ is not likely the result fusion pore regulation or spillover, suggesting that the elevated glutamate transient is attributable to MVR.

Release probability determines MVR

Our results imply that the likelihood of MVR depends on $P_{\mathrm{r}}$. This relationship was further examined by comparing the $\gamma$-DGG sensitivity of EPSCs evoked in different extracellular calcium $\left(\mathrm{Ca}_{\mathrm{e}}^{+2}\right)$ concentrations. Because vesicle fusion and transmitter release are calcium dependent, manipulations of the $\mathrm{Ca}^{+2}$ concentration potently alter calcium influx and therefore the probability of vesicle release (Zucker and Regehr, 2002; Schneggenburger and Neher, 2005). $\gamma$-DGG (2 mM) inhibited AMPA EPSCs, evoked by a single stimulation, to the same extent in 1.25 and $1.5 \mathrm{~mm}$ $\mathrm{Ca}_{\mathrm{e}}^{+2}$ in an across-cell comparison (Fig. $4 A$, top, $B_{1}$ ). This suggests that MVR is not significant after a single stimulation at either $\mathrm{Ca}^{+2}{ }_{\mathrm{e}}$ concentration. However, in the presence of $2.5 \mathrm{mM} \mathrm{Ca}^{+2}$ e, $\gamma$-DGG inhibition was reduced (Fig. $4 A$, top, $B_{1}$ ) compared with 1.25 or $1.5 \mathrm{~mm} \mathrm{Ca}^{+2}$, indicating an increase in the synaptic glutamate concentration. EPSC inhibition by NBQX $(400 \mathrm{nM})$ was not dependent on the $\mathrm{Ca}^{+2}{ }_{\mathrm{e}}$ (Fig. $4 A$, bottom, $B_{2}$ ). These results are consistent with the increased likelihood of MVR when $P_{\mathrm{r}}$ is elevated.

The effect of $\gamma$-DGG (2 mM) on PPF was also determined in different $\mathrm{Ca}^{+2}$ e conditions. In $1.25 \mathrm{mM} \mathrm{Ca}^{+2}$, $\gamma$-DGG inhibited EPSC $_{1}$ to the same extent as EPSC $_{2}$; consequently, the PPR remained unchanged $(2.03 \pm 0.13$ and $2.08 \pm 0.11$, control and $\gamma$-DGG, respectively; $n=5$ ) (Fig. $4 C_{1}, C_{2}, C_{3}$ ). The absence of an effect of $\gamma$-DGG on facilitation suggests that MVR is negligible in $1.25 \mathrm{mM} \mathrm{Ca}^{+2}$ and that PPF reflects recruitment of additional single vesicle-releasing synapses. In 2.5 $\mathrm{mM} \mathrm{Ca}{ }^{+2}$, $\gamma$-DGG elicited a small, albeit variable, increase in the PPR $(1.79 \pm 0.12$ and $2.08 \pm 0.19$, control and $\gamma$-DGG, respectively; $n=7 ; p<0.05)$. NBQX did not affect the PPR $(1.83 \pm 0.13 ; n=7)$ (Fig. $\left.4 D_{1}, D_{2}, D_{3}\right)$. This indicates that the concentration of cleft glutamate evoked by first stimulus is lower, on average, than by the second in $2.5 \mathrm{~mm}$ $\mathrm{Ca}^{+2}$ e. However, $\gamma$-DGG inhibited both EPSC $_{1}$ and EPSC $_{2}$ less effectively in $2.5 \mathrm{mM} \mathrm{Ca}^{+2}$ e than in lower $\mathrm{Ca}^{+2}{ }_{\mathrm{e}}$ concentrations. 
This suggests that MVR occurs after both stimulations. Because the evoked glutamate transients are similar in $2.5 \mathrm{~mm}$ $\mathrm{Ca}^{+2}$, DGG does not affect PPR as much as it does in $1.5 \mathrm{~mm} \mathrm{Ca}_{\mathrm{e}}^{+2}$ (Fig. 1).

\section{NMDA receptors and MVR}

Blocking glutamate uptake prolongs NMDA receptor-mediated EPSCs in hippocampus, an effect attributed to glutamate spillover onto neighboring synaptic or extrasynaptic receptors (Diamond, 2001; Arnth-Jensen et al., 2002). The cooperative release of transmitter from multiple presynaptic sites can enhance the magnitude of glutamate spillover detected by NMDA receptors (Arnth-Jensen et al., 2002). Release of multiple vesicles from the same terminal could produce a similar effect. We examined this possibility by comparing the TBOA-mediated prolongation of NMDA EPSCs in conditions that favor UVR (low $P_{\mathrm{r}}$ ) or MVR (high $P_{\mathrm{r}}$ ) (Fig. $\left.5 A_{1}, A_{2}\right)$.

NMDA receptor-mediated EPSCs were evoked with a single stimulation and $P_{\mathrm{r}}$ was altered by changing $\mathrm{Ca}^{+2}$ from 1.5 to $2.5 \mathrm{~mm}$. We qualitatively normalized the number of active synapses by reducing the stimulation intensity so that the amplitude of the EPSC evoked in $2.5 \mathrm{mM} \mathrm{Ca}^{+2}$ e approximated the amplitude of the EPSC in 1.5 $\mathrm{mM} \mathrm{Ca}_{\mathrm{e}}^{+2}$. TBOA $(10 \mu \mathrm{M})$ prolonged both the first and second decay time constants (Fig. $5 B_{1}$ ) and increased the integral of the EPSC (Fig. $5 B_{2}$ ) significantly more in $2.5 \mathrm{mM} \mathrm{Ca}^{+2}$ e than in 1.5 $\mathrm{mM} \mathrm{Ca}{ }^{+2}$. In contrast, TBOA increased the EPSC amplitude in 1.5 and $2.5 \mathrm{mM} \mathrm{Ca}^{+2}$ to the same extent (Fig. $5 B_{2}$ ). Diamond (2001) also found that the amplitude increase elicited by TBOA was not sensitive to the magnitude of spillover. These results suggest that MVR increases the amount of glutamate spillover during uptake inhibition. To determine whether MVR contributes to spillover when uptake is intact, we compared the decay time course of control EPSCs evoked in 1.5 and $2.5 \mathrm{mM} \mathrm{Ca}^{+2}$ e (Fig. 5C). Although $\tau_{1}$ was not different $(27.9 \pm 1.0$ and $26.3 \pm$ $1.5 \mathrm{~ms}, 1.5$ and $2.5 \mathrm{mM} \mathrm{Ca}^{+2}$, respectively; $n=13$ ), a slight but significant increase was found in $\tau_{2}(137.1 \pm 2.9$ and $147 \pm 4.1$ ms, 1.5 and $2.5 \mathrm{~mm} \mathrm{Ca}^{+2}$ e, respectively; $\left.n=13 ; p<0.05\right)$. This prolongation indicates that low concentrations of glutamate are present longer in conditions of heightened MVR and suggests that glutamate transporters, even in the absence of TBOA, clear glutamate more slowly in these conditions.

\section{Discussion}

\section{Neurotransmission at SC-CA1 synapses}

We studied the relationship between $P_{\mathrm{r}}$ and the evoked concentration of glutamate release using rapidly equilibrating antagonists (Clements et al., 1992; Tong and Jahr, 1994; Wadiche and Jahr, 2001) and found that the glutamate transient detected by AMPA receptors was enhanced during synaptic facilitation, a result consistent with MVR. Models of release predict that synaptic facilitation depends on an increase in the number and/or $P_{\mathrm{r}}$ of available vesicles (Zucker, 1989). Presynaptic active zones of SCCA1 synapses have between 2 and 27 docked vesicles (Schikorski and Stevens, 1997), and each docked vesicle may represent a po- tential site of release (Schikorski and Stevens, 2001). If vesicles are released in a probabilistic manner, active zones with greater numbers of docked vesicles will have a higher probability of releasing vesicles. Given the variability in the number of docked vesicles among SC-CA1 synapses and the range in $P_{\mathrm{r}}$ (Dobrunz et al., 1997; Hanse and Gustafsson, 2001), the number of potentially releasable vesicles from synapse to synapse could be highly variable. Because repetitive presynaptic activity can cause facilitation of release, i.e., an increased $P_{\mathrm{r}}$, MVR becomes more likely with repeated stimulation.

Previous examinations of SC-CA1 synapses found that the potency of AMPA receptor EPSCs evoked by minimal stimulation was not altered by changing $P_{\mathrm{r}}$, thereby arguing against MVR (Stevens and Wang, 1995; Hjelmstad et al., 1997; Hanse and Gustafsson, 2001). However, the criteria by which single synapses are selected in minimal stimulation experiments will reject those that release more than a single vesicle. In contrast, optical measurements of NMDA receptor-mediated calcium transients in single spines suggested that potency increases with $P_{\mathrm{r}}$, arguing in favor of MVR (Oertner et al., 2002; Conti and Lisman, 2003). Theoretically, these results could be also explained by enhanced spillover from neighboring release sites (Barbour and Häusser, 1997; Rusakov and Kullmann, 1998) or perhaps fusion pore regulation that controls the rate of transmitter release (Choi et al., 2000; Renger et al., 2001). We used the low-affinity antagonist approach to qualitatively assess transmitter release across a population of active synapses (Tong and Jahr, 1994; Wadiche and Jahr, 2001). Because of the possibility of non-overlapping release sites on the same synapse (Raghavachari and Lisman, 2004), this technique may underreport the frequency of multivesicular release.

\section{MVR, spillover, and fusion pore regulation}

When released simultaneously from multiple sites, glutamate can accumulate and spillover to adjacent synapses, altering the synaptic glutamate waveform (Takahashi et al., 1995; Arnth- 
Jensen et al., 2002; Clark and Cull-Candy, 2002; DiGregorio et al., 2002). However, we found that spillover of glutamate is unlikely to contribute to the peak amplitude of the AMPA receptor EPSC because enhancing spillover did not affect inhibition by $\gamma$-DGG. The time course of transmitter diffusion to neighboring sites depends on intersite distance and geometry (Barbour and Häusser, 1997; Rusakov and Kullmann, 1998). The hippocampal neuropil is a tortuous environment with generally well separated release sites (Ventura and Harris, 1999), conditions that both diminish and slow diffusion of transmitter from one synapse to its neighbors. Even at mossy fiber-granule cell synapses in the cerebellum in which release sites are densely packed, spillover currents are slow to rise compared with events evoked by local release and contribute only slightly to the peak amplitude of the direct EPSC (DiGregorio et al., 2002; Nielsen et al., 2004; Sargent et al., 2005).

In contrast to AMPA receptor EPSCs, the decay kinetics of NMDA receptor EPSCs were prolonged when glutamate uptake was inhibited, consistent with a slow spillover-mediated transient of transmitter (Asztely et al., 1997; Diamond, 2001; Arnth-Jensen et al., 2002). Because NMDA receptors have a higher affinity for glutamate binding than NMDA receptors (Patneau and Mayer, 1990), NMDA receptors are more likely to be activated by low levels of glutamate diffusing from adjacent release sites (Renger et al., 2001). Thus, glutamate spillover preferentially activates NMDA receptors but not AMPA receptors (Asztely et al., 1997; Diamond, 2001; Clark and Cull-Candy, 2002) at SC-CA1 synapses.

The magnitude of spillover is exacerbated when $P_{\mathrm{r}}$ is elevated because exocytosis occurs at many additional release sites, increasing the density of release and thereby the overlap of glutamate diffusion domains (Arnth-Jensen et al., 2002). Our results indicate that $P_{\mathrm{r}}$-dependent recruitment of MVR also contributes to the extrasynaptic glutamate transient. We found that spilloverdependent prolongation of NMDA receptor responses was greater in conditions that favor MVR. However, this prolongation was robust only when glutamate uptake was inhibited, suggesting that uptake is generally sufficient to control the diffusion of glutamate in stratum radiatum of CA1 (Bergles and Jahr, 1998; Diamond and Jahr, 2000). It remains undetermined whether MVR can contribute significantly to glutamate spillover during intense physiological activity, such as bursting (Arnth-Jensen et al., 2002).

Fusion pore regulation has also been suggested to control the glutamate transient at CA1 synapses (Choi et al., 2000; Renger et al., 2001). When such regulation occurs, the kinetics of AMPA receptor-mediated EPSCs are slowed (Choi et al., 2000). We found, however, that the EPSC rise and decay did not change when $P_{\mathrm{r}}$ was altered, suggesting that fusion pore regulation cannot account for our results.

\section{Ubiquity of MVR}

Both conventional (Auger et al., 1998; Wadiche and Jahr, 2001; Foster et al., 2002; Oertner et al., 2002; Watanabe et al., 2005) and ribbon (Glowatzki and Fuchs, 2002; Singer et al., 2004) synapses have been reported to release multiple vesicles under physiological conditions. At some synapses, then, release is not restricted to a single vesicle, but rather vesicles are released independently in a probabilistic manner and the number of vesicles released per stimulus increases with $P_{\mathrm{r}}$. However, observations of MVR at conventional synapses have been mainly limited to high $P_{\mathrm{r}}$ sites. The work presented here extends MVR to moderate and low $P_{\mathrm{r}}$ synapses, suggesting that the initial $P_{\mathrm{r}}$ of a synapse does not necessarily limit MVR. Instead, MVR depends on the $P_{\mathrm{r}}$ at the time of release. This suggests that the use-dependent mechanisms that alter $P_{\mathrm{r}}$, such as frequency facilitation and depression (Zucker and Regehr, 2002), as well as receptor-mediated release modulation (Wu and Saggau, 1997) and long-term presynaptic plasticity (Malenka and Bear, 2004), may play a predominant role in the expression of MVR.

Despite reports of MVR at a number of synapses, it apparently is not a ubiquitous phenomenon. Korn et al. $(1981,1982)$ found that the number of anatomically observed presynaptic terminals closely approximated the number of functionally identified release sites between goldfish Mauthner cells and interneurons. This result implied that release was limited to a single vesicle per synapse. Studies examining transmission at other central synapses have bolstered support for UVR (Redman and Walmsley, 1983; Gulyás et al., 1993; Lawrence et al., 2003; Silver et al., 2003; Murphy et al., 2004; Biró et al., 2005). Given that numerous vesicles are ultrastructurally docked at many presynaptic active zones and constitute a readily releasable pool of functional vesicles (Lenzi et al., 1999; Schikorski and Stevens, 2001; XuFriedman et al., 2001), a mechanism must exist to prevent multiple fusion events at synapses limited to UVR. A combination of multiple structural and molecular components may contribute to this phenomenon. For example, it may be that the SNARE (soluble $N$-ethylmaleimide-sensitive fusion protein-attachment protein receptor) complex and its diverse assemblage of proteins (Harlow et al., 2001; Südhof, 2002; Jahn et al., 2003) can, at some synapses, signal the impending release of one vesicle to its neighboring vesicles.

\section{Physiological significance}

Our results suggest that MVR contributes to facilitation at SCCA1 synapses. Because short-term enhancement of synaptic transmission can improve the strength and reliability of intercellular communication (Blitz et al., 2004), we expect that MVR plays a crucial role in determining the input-output relationship between cells in the hippocampal SC-CA1 microcircuit. During periods of sparse SC spiking, MVR is less likely because the intrinsic $P_{\mathrm{r}}$ remains low. However, MVR would become prominent during high-frequency bursts of activity and contribute to the facilitation of the postsynaptic potential and the likelihood of action potential initiation.

MVR may be a dynamic process and could be influenced by the expression of other types of plasticity. SC-CA1 synapses reflect a diverse population with a wide range of synapse sizes, the number of release-ready vesicles, and release probabilities (Harris and Stevens, 1989; Schikorski and Stevens, 1997; Schikorski and Stevens, 2001). Reports of activity-dependent changes in spine size (Matsuzaki et al., 2004) suggest that these subpopulations are not static but, in fact, are interchangeable. If MVR is a function of $P_{\mathrm{r}}$, then it will occur more often at presynaptically potentiated synapses than depressed synapses.

\section{References}

Arnth-Jensen N, Jabaudon D, Scanziani M (2002) Cooperation between independent hippocampal synapses is controlled by glutamate uptake. Nat Neurosci 5:325-331.

Asztely F, Erdemli G, Kullmann D (1997) Extrasynaptic glutamate spillover in the hippocampus: the role of active glutamate uptake. Neuron 18:281-293.

Auger C, Kondo S, Marty A (1998) Multivesicular release at single functional synaptic sites in cerebellar stellate and basket cells. J Neurosci 18:4532-4547.

Barbour B, Häusser M (1997) Intersynaptic diffusion of neurotransmitter. Trends Neurosci 20:377-384.

Bergles DE, Jahr CE (1997) Synaptic activation of glutamate transporters in hippocampal astrocytes. Neuron 19:1297-1308.

Bergles DE, Jahr CE (1998) Glial contribution to glutamate uptake at Schaf- 
fer collateral-commissural synapses in the hippocampus. J Neurosci 18:7709-7716.

Biró ÁA, Holderith N, Nusser Z (2005) Quantal size is independent of the release probability at hippocampal excitatory synapses. J Neurosci 25:223-232.

Blitz D, Foster KA, Regehr WG (2004) Short-term synaptic plasticity: a comparison of two synapses. Nat Rev Neurosci 5:630-640.

Choi S, Klingauf J, Tsien RW (2000) Postfusional regulation of cleft glutamate concentration during LTP at "silent synapses." Nat Neurosci 3:330-336.

Clark BA, Cull-Candy SG (2002) Activity-dependent recruitment of extrasynaptic NMDA receptor activation at an AMPA receptor-only synapse. J Neurosci 22:4428-4436.

Clements JD, Lester RA, Tong G, Jahr CE, Westbrook GL (1992) The time course of glutamate in the synaptic cleft. Science 258:1498-1501.

Conti R, Lisman J (2003) The high variance of AMPA receptor- and NMDA receptor-mediated responses at single hippocampal synapses: evidence for multiquantal release. Pro Natl Acad Sci USA 100:4885-4890.

Diamond JS (2001) Neuronal glutamate transporters limit activation of NMDA receptors by neurotransmitter spillover on CA1 pyramidal cells. J Neurosci 21:8328-8338.

Diamond JS, Jahr CE (2000) Synaptically released glutamate does not overwhelm transporters on hippocampal astrocytes during high-frequency stimulation. J Neurophysiol 83:2835-2843.

DiGregorio DA, Nusser Z, Silver RA (2002) Spillover of glutamate onto synaptic AMPA receptors enhances fast transmission at a cerebellar synapse. Neuron 35:521-533.

Dobrunz LE, Huang EP, Stevens CF (1997) Very short-term plasticity in hippocampal synapses. Proc Natl Acad Sci USA 94:1483-1487.

Foster KA, Kreitzer AC, Regehr WG (2002) Interaction of postsynaptic receptor saturation with presynaptic mechanisms produces a reliable synapse. Neuron 35:1115-1126.

Glowatzki E, Fuchs PA (2002) Transmitter release at the hair cell ribbon synapse. Nat Neurosci 5:147-154.

Gulyás AI, Miles R, Sik A, Toth N, Tamamaki N, Freund TF (1993) Hippocampal pyramidal cells excite inhibitory neurons through a single release site. Nature 366:683-687.

Hanse E, Gustafsson B (2001) Factors explaining heterogeneity in shortterm synaptic dynamics of hippocampal glutamatergic synapses in the neonatal rat. J Physiol (Lond) 537:141-149.

Harlow ML, Ress D, Stoschek A, Marshall RA, McMahan UJ (2001) The architecture of active zone material at the frog's neuromuscular junction. Nature 409:479-484.

Harris KM, Stevens JK (1989) Dendritic spines of CA1 pyramidal cells in the rat hippocampus: serial electron microscopy with reference to their biophysical characteristics. J Neurosci 9:2982-2997.

Hestrin S, Sah P, Nicoll RA (1990) Mechanisms generating the time course of dual component excitatory synaptic currents recorded in hippocampal slices. Neuron 5:247-253.

Hjelmstad GO, Nicoll RA, Malenka RC (1997) Synaptic refractory period provides a measure of probability of release in the hippocampus. Neuron 19:1309-1318.

Jahn R, Lang T, Südhof TC (2003) Membrane fusion. Cell 112:519-533.

Korn H, Triller A, Mallet A, Faber DS (1981) Fluctuating responses at a central synapse: $n$ of binomial fit predicts number of stained presynaptic boutons. Science 213:898-901.

Korn H, Mallet A, Trilller A, Faber DS (1982) Transmission at a central inhibitory synapse. II. Quantal description of release, with a physical correlate for binomial $n$. J Neurophysiol 48:697-707.

Lawrence JJ, Grinspan ZM, McBain CJ (2003) Quantal transmission at mossy fibre targets in the CA3 region of the rat hippocampus. J Physiol (Lond) 554:175-193.

Lehre KP, Danbolt NC (1998) The number of glutamate transporter subtype molecules at glutamatergic synapses: chemical and stereological quantification in young adult rat brain. J Neurosci 18:8751-8757.

Lenzi D, Runyeon JW, Crum J, Ellisman MH, Roberts WM (1999) Synaptic vesicle populations in saccular hair cells reconstructed by electron tomography. J Neurosci 19:119-132.

Liu G, Choi S, Tsien RW (1999) Variability of neurotransmitter concentration and nonsaturation of postsynaptic AMPA receptors at synapses in hippocampal cultures and slices. Neuron 22:395-409.

Malenka RC, Bear MF (2004) LTP and LTD: an embarrassment of riches. Neuron 44:5-21.
Matsuzaki M, Honkura N, Ellis-Davies GCR, Kasai H (2004) Structural basis of long-term potentiation in single dendritic spines. Nature 429:761-766.

Murphy GJ, Glickfeld LL, Balsen Z, Isaacson JS (2004) Sensory neuron signaling to the brain: properties of transmitter release from olfactory nerve terminals. J Neurosci 24:3023-3030.

Nielsen TA, DiGregorio DA, Silver RA (2004) Modulation of glutamate mobility reveals mechanism of underlying slow-rising AMPA EPSCs and the diffusion coefficient in the synaptic cleft. Neuron 42:757-771.

Oertner TG, Sabatini BL, Nimchinsky EA, Svoboda K (2002) Facilitation at single synapses probed with optical quantal analysis. Nat Neurosci 7:657-664.

Patneau DK, Mayer ML (1990) Structure-activity relationships for amino acid transmitter candidates acting at $N$-methyl-D-aspartate and quisqualate receptors. J Neurosci 10:2385-2399.

Raghavachari S, Lisman JE (2004) Properties of quantal transmission at CA1 synapses. J Neurophysiol 92:2456-2467.

Redman SJ, Walmsley B (1983) Amplitude fluctuations in synaptic potentials evoked in cat spinal motoneurons at identified group 1a synapses. J Physiol (Lond) 343:135-145.

Renger JJ, Egles C, Liu G (2001) A developmental switch in neurotransmitter flux enhances synaptic efficacy by affecting AMPA receptor activation. Neuron 29:469-484.

Rusakov DA, Kullmann DM (1998) Extrasynaptic glutamate diffusion in the hippocampus: ultrastructural constraints, uptake, and receptor activation. J Neurosci 18:3158-3170.

Sarantis M, Ballerini L, Miller B, Silver RA, Edwards M, Attwell D (1993) Glutamate uptake from the synaptic cleft does not shape the decay of the nonNMDA component of the synaptic current. Neuron 11:541-549.

Sargent PB, Saviane C, Nielsen TA, DiGregorio DA, Silver RA (2005) Rapid vesicular release, quantal variability, and spillover contribute to the precision and reliability of transmission at a glomerular synapse. J Neurosci 25:8173-8187.

Scanziani M, Salin PA, Vogt KE, Malenka RC, Nicoll RA (1997) Usedependent increases in glutamate concentration activate presynaptic metabotropic glutamate receptors. Nature 385:630-634.

Schikorski T, Stevens CF (1997) Quantitative ultrastructural analysis of hippocampal excitatory synapses. J Neurosci 17:5858-5867.

Schikorski T, Stevens CF (2001) Morphological correlates of functionally defined synaptic vesicle populations. Nat Neurosci 4:391-395.

Schneggenburger R, Neher E (2005) Presynaptic calcium and control of vesicle fusion. Curr Opin Neurobiol 15:266-274.

Silver RA, Lübke J, Sakmann B, Feldmeyer D (2003) High-probability uniquantal transmission at excitatory synapses in barrel cortex. Science 302:1981-1984

Singer JH, Lassová L, Vardi N, Diamond JS (2004) Coordinated multivesicular release at a mammalian ribbon synapse. Nat Neurosci 8:826-833.

Stevens CF, Wang Y (1995) Facilitation and depression at single central synapses. Neuron 14:795-802.

Südhof T (2002) Synaptotagmins: why so many? J Biol Chem 277:7629-7632.

Takahashi M, Kovalchuk Y, Attwell D (1995) Presynaptic and postsynaptic determinants of EPSC waveform at cerebellar climbing fiber and parallel fiber to Purkinje cell synapses. J Neurosci 15:5693-5702.

Tong G, Jahr CE (1994) Multivesicular release from excitatory synapses of cultured hippocampal neurons. Neuron 12:51-59.

Ventura R, Harris KM (1999) Three-dimensional relationships between hippocampal synapses and astrocytes. J Neurosci 19:6897-6906.

Wadiche JI, Jahr CE (2001) Multivesicular release at climbing fiberPurkinje cell synapses. Neuron 32:301-313.

Watanabe J, Rozov A, Wollmuth LP (2005) Target-specific regulation of synaptic amplitudes in the neocortex. J Neurosci 25:1024-1033.

Watkins JC, Pook PCK, Sunter DC, Davies J, Honore T (1990) Experiments with kainite and quisqualate agonists and antagonists in relation to the sub-classification of "non-NMDA" receptors. Excitatory amino acids and neuronal plasticity. New York: Plenum.

Wu LG, Saggau P (1997) Presynaptic inhibition of elicited neurotransmitter release. Trends Neurosci 20:204-212.

Xu-Friedman MA, Harris KM, Regehr WG (2001) Three-dimensional comparison of ultrastructural characteristics at depressing and facilitating synapses onto cerebellar Purkinje cells. J Neurosci 21:6666-6672.

Zucker RS (1989) Short-term synaptic plasticity. Annu Rev Neurosci 12:13-31.

Zucker RS, Regehr WG (2002) Short-term synaptic plasticity. Annu Rev Physiol 64:355-405. 